\title{
Molecular Prognosis of Endometrial Adenocarcinoma by Expression Patterns of the V-ATPase C1 Subunit
}

Abdalla Dib Chacur ${ }^{1,3 *}$, Juliana Couto-Viera ${ }^{1 *}$, Anna Okorokova Façanha ${ }^{2}$, Glenerson Baptista1 ${ }^{1}$ Arnoldo Rocha Façanha1.

${ }^{1}$ Laboratório de Biologia Celular e Tecidual and ${ }^{2}$ Laboratório de Bioquímica e Fisiologia de Microrganismos, Centro de Biociências e Biotecnologia, Universidade Estadual do Norte Fluminense Darcy Ribeiro, Campos dos Goytacazes, RJ, Brazil; ${ }^{3}$ Faculdade de Medicina de Campos, Campos dos Goytacazes, RJ, Brazil.

* These authors contributed equally to this work.

Corresponding author: arnoldo@uenf.br 


\begin{abstract}
- Comparative analysis of expression patterns of ATP6V1C1 encoding $\mathrm{C} 1$ subunit of $\mathrm{V}-\mathrm{H}^{+}$-ATPase revealed that molecular alterations correlated with endometrial cancer of better prognosis were grouped with low ATP6V1C1 expression while those correlated with worse prognosis were clustered with high ATP6V1C1 expression levels.

- Expression patterns of C1 subunit in endometrial adenocarcinoma are associated with molecular malignancy signatures shared by histological subtypes of highest mortality rate suggesting that G3 adenocarcinoma exhibits molecular changes resembling endometrial serous carcinoma.

- ATP6V1C1 might serve as novel prognostic marker allowing identification of targetable pathways for high-risk endometrial cancer.
\end{abstract}

Keywords: ATP6V1C1; cancer biomarker; endometrial cancer; V-ATPase; C1 isoform; $\mathrm{H}^{+}$signatures.

\title{
Main
}

Endometrial cancer (EC) was estimated to be the second most incident gynecological cancer in the world, and is classified into two subtypes, a low-grade Type I (UEC, uterine endometrioid carcinoma), the most common EC, usually estrogen dependent, carrying a good prognosis; and a Type II, including endometrial serous histological subtype (USC, uterine serous carcinoma), often not associated with increased estrogen exposure, carrying a poor prognosis [1]. 
Although usually diagnosed in early stages, the survival rate of UEC decreases when associated with worse prognosis criteria. Identification of molecular patterns related to an unfavorable evolution would allow a better understanding of the oncogenic process and, hence, individualized and more accurate therapies, preventing avoidable radical treatments involving aggressive surgery, radiation and multimodal chemotherapy.

The vacuolar/lysosomal $\mathrm{H}^{+}$-ATPase (V-ATPase), a multisubunit protein complex, is important for acidification-dependent degradation of tissue matrices allowing cell migration and plays a key role in $\mathrm{pH}$ regulation across epithelial cell layers, including during placentation, which involves intricate signaling, cell proliferation, and controlled invasion [2]. It was also shown that progesteroneinduced decrease in uterine fluid $\mathrm{pH}$ involves the functional overexpression of the V-ATPase, as suggested by the expression patterns of subunits of the catalytic domain (A1 and B1/2), which were found to be highly expressed throughout the uterine luminal and glandular epithelia [3]. Epithelial expression of V-ATPase subunits in nonpregnant animals exhibits an apical abundance, however, as pregnancy proceed, the expression of these subunits became luminally pericellular, excepting in glandular epithelium, indicating a specific spatialtemporal membrane targeting redistribution of V-ATPases [2]. Furthermore, ectocervical cells acidify the vaginal canal by a mechanism of $\mathrm{H}^{+}$pumping driven by $\mathrm{V}$-ATPases located in cell apical plasma membranes, and this active net $\mathrm{H}^{+}$ secretion occurs constitutively throughout life, with acidification cycles upregulated by estrogen [4]. Estrogen also induces proliferation of endometrial glands and tissues hyperplasia. In patients at risk, an accumulation of genetic damage led to proliferation of mutant clones under the mitogenic stimulus of 
estrogen, triggering histological changes that can culminate in malignant transformation [5].

Regarding these functional relationships of V-ATPases with the acid metabolism of female reproductive system, it is perhaps not surprising that specific modulations in functional expression of this pump has been associated with the acid metabolic reprogramming of different gynecologic cancers (e.g., [6]). However, the study of expression profiles of this enzyme is not trivial, since VATPases are composed of 13 subunits, divided into eight peripheral proteins grouped in a cytoplasmic V1 domain $(\mathrm{A}-\mathrm{H})$, responsible for the hydrolysis of ATP, and five intrinsic membrane proteins composing a V0 domain, represented by subunits a, c, c", d and e. In mammals, some subunits of the enzyme have different isoforms. The $\mathrm{C}$ subunit which is important for the reversible structural and functional coupling of the $\mathrm{V} 1$ and $\mathrm{V} 0$ domains, has three isoforms in humans, namely $\mathrm{C} 1, \mathrm{C} 2 \mathrm{a}$ and $\mathrm{C} 2 \mathrm{~b}[7]$.

The $\mathrm{C} 1$ isoform of subunit $\mathrm{C}$ of this oligomeric enzyme has been associated with an assembly of the holoenzyme of greater catalytic efficiency, related to a higher coupling between the $\mathrm{V} 1$ and $\mathrm{V} 0$ domains, and thus, the expression profile of this subunit has received increasing attention by its differential expression in different tumor cells (e.g., [8]), leading to a reprogramming of intra- and extracellular $\mathrm{pH}$ homeostasis $[9,10]$, and even in nucleoplasm [11]. Disruption of cellular $\mathrm{pH}$ homeostasis is a hallmark of most types of cancer, regardless of their genetic or tissue origin [11]. A neutral-slightly alkaline intracellular $\mathrm{pH}$ is permissive to cell proliferation and evasion of apoptosis, whereas the decrease in extracellular $\mathrm{pH}$ favors the evasion of the immune response against the tumor, promotes the extracellular matrix 
remodeling and stimulates acid-activated proteases, facilitating the invasion and dissemination of tumor cells [12]. Tumor cell metastasis also depends on secreted lysosomal enzymes that participate in the extracellular matrix degradation and cell to cell detachment, which in turn, is related to altered expression profile of adhesion cell molecules. Lysosomal enzymes require a low $\mathrm{pH}$ for optimal activity, and in tumor cells V-ATPases regulate acidification of extracellular microenvironment [13].

Here, we used the Cancer Genome Atlas (TCGA) database to identify putative clustering expression patterns associated with the $\mathrm{C} 1$ isoform in UEC that could refine prognosis and identify targetable pathways for high-risk UEC. Genomic and clinical data on TCGA endometrial carcinoma were accessed through the CBioPortal (www.cbioportal.org)/ PanCancer database $(n=529)$. The histological type selected was UEC ( $n=399)$, which represented $75.4 \%$ of the available cases, among these 397 had expression information by RNA-seq (RNAseq V2 RSEM), representing $99.5 \%$ of the samples. Levels of mRNA were evaluated for $\mathrm{V}$-ATPase genes representing $\mathrm{V} 1$ domain and V0 domain, totalizing 25 genes. Clinical-pathological information was collected regarding mutation, staging, histological grade, percentage of invasion, survival; genetic alterations in V-ATPase genes expressed in UEC were analyzed and expression heatmaps of genes with similar patterns of ATP6V1C1 expression were verified. Analysis of gene expression patterns according to histologic grade and significant genes coexpression was also performed. Comparison between two expression groups (ATP6V1C1 of high >1 and low <-1 expression profiles) was performed in relation to the histological grade and the most incident genetic mutations. We also analyzed the correlation between the differential patterns of ATP6V1C1 
expression in relation to selected clustered expression genes and proteins. Statistical analysis was obtained from the cBioPortal platform, considered significant $(p<0.005)$.

Data were analyzed according to the differential ATP6V1C1 mRNA levels (high and low C1 isoform expression patterns). Remarkably, UEC grade 1 and 2 exhibited low expression of ATP6V1C1, while both G3 UEC and G3/high grade USC exhibited high ATP6V1C1 expression (Suppl. Fig. S1 and Fig. 1a,d). Moreover, a few genetic alterations found in ATP6V1C1 correlated well with high C1 expression and G3 tumor grade (Suppl. Fig. S2). Analysis of only the G3 UEC showed better overall survival linked to medium ATP6V1C1 expression levels (Suppl. Fig. S2), suggesting that regular expression of V-ATPase isoform C1 is a significant factor influencing treatment responsiveness.

Endometrial carcinomas also differ on a molecular basis, i.e., PTEN and PIK3CA which are often mutated in UEC [14], are scarcely altered in USC. On the other hand, mutations of p53 are often observed in USC, but are barely found in UEC (e.g., [1]). Clustering analysis revealed that among the genes clustered with ATP6V1C1 low expression in UEC, the most frequently mutated gene was PTEN (Fig. 1b), characteristic of tumors with a better prognosis, while mutated TP53, associated with a poor prognosis [1], clustered with C1 high expression group (Fig. 1b; $p=1.95 e-7)$, which in turn, exhibit a tumor grade pattern resembling that of USC (Fig.1e). Furthermore, high ATP6V1C1 expression in UEC could also be associated with molecular malignancy signatures, shared by the USC histological subtype, correlated with highest mortality rates (Fig. 1 a,d). Kaplan-Meier curve of ATP6V1C1 expression in relation to progression-free 
survival indicated significant difference between low and high groups, with high ATP6V1C1 UEC similar to USC profile (Fig. $1 \mathrm{c}, \mathrm{f})$.

Previously, TCGA analyses on the expression of V-ATPase genes in both subtypes of esophageal cancer, squamous cell carcinoma and adenocarcinoma, demonstrated that the expression of $\mathrm{C} 1$ isoform was higher in relation to $\mathrm{C} 2 \mathrm{a}, \mathrm{b}$ isoforms (data validated by qRT-PCR), and that this disproportion between C1 and $\mathrm{C} 2 \mathrm{a}, \mathrm{b}$ mRNA expressions levels was able to differentiate neoplasia from normal tissues [8]. The present data taken together with our previous multicancer analyses [8], provide compelling evidence for the differential expression of the $\mathrm{H}^{+}$ pump subunit $\mathrm{C}$ isoforms (especially the dominance of $\mathrm{C} 1$ ) as promising cancer biomarkers. These findings also contributed to the understanding of the role of the V-ATPase complex in tumorigenesis and how this pump can potentiate multiple signaling pathways in coordination with key oncogenes and tumor suppressor genes in UEC [15].

In conclusion, this work opens a new avenue for clinical-pathological studies, which will determine whether this reported molecular phenotyping can be clinically validated and whether expression differences in $\mathrm{C} 1$ subunit and other V-ATPase related molecular signatures could be exploited for pathological diagnosis, prognosis and/or targeted therapy, as well as to further understanding of the acid reprogramming metabolism of EC and other related cancers.

\section{Acknowledgments}

This work was supported by the CNPq (Conselho Nacional de Desenvolvimento Científico e Tecnológico), FAPERJ (Fundação de Amparo à Pesquisa do Estado do Rio de Janeiro) and Universidade Estadual do Norte Fluminense Darcy 
Ribeiro (UENF). This study was financed in part by the Coordenação de Aperfeiçoamento de Pessoal de Nível Superior - Brasil (CAPES) - Finance Code 001.

\section{References}

[1] K. Nakayama, K. Nakayama, M. Ishikawa, K. Miyazaki, Endometrial serous carcinoma: its molecular characteristics and histology-specific treatment strategies. Cancers, 4(2012) 799-807. https://doi.org/10.3390/cancers4030799. [2] M.A. Skinner MA, L.A. MacLaren, A.G. Wildeman, Stage-dependent redistribution of the V-ATPase during bovine implantation. J. Histochem. Cytochem. 47 (1999) 1247-1254. https://doi.org/10.1177/002215549904701004. [3] K. Karim, N. Giribabu, S.Muniandy, N. Salleh, Vacuolar-ATPase (V-ATPase) Mediates Progesterone-Induced Uterine Fluid Acidification in Rats. J Membr Biol. 249(2016):65-76. https://doi.org/10.1007/s00232-015-9848-z.

[4] G. I. Gorodeski, U. Hopfer, C.C. Liu, E. Margles, Estrogen acidifies vaginal pH by up-regulation of proton secretion via the apical membrane of vaginalectocervical epithelial cells. Endocrinol. 146(2005) 816-824. https://doi.org/10.1210/en.2004-1153.

[5] P. A. Sanderson, New concepts for an old problem: the diagnosis of endometrial hyperplasia. Hum. Reprod. Update. 23(2017) 232-254. https://doi.org/10.1093/humupd/dmw042.

[6] A. Kulshrestha, G.K. Katara, S. Ibrahim et al., Vacuolar ATPase 'a2' isoform exhibits distinct cell surface accumulation and modulates matrix metalloproteinase activity in ovarian cancer. Oncotarget. 6(2015) 3797-3810. https://doi.org/10.18632/oncotarget.2902. 
[7] K. Cotter, L. Stransky, C. McGuire, M. Forgac, Recent Insights into the Structure, Regulation, and Function of the V-ATPases. Trends Biochem. Sci. 40(2015) 611-622. https://doi.org/10.1016/j.tibs.2015.08.005.

[8] G.A. Costa, S.B. de Souza, L.R. da Silva Teixeira, L.A. Okorokov, A.C.V. Arnholdt, A.L..Okorokova-Façanha, A.R. Façanha, Tumor cell cholesterol depletion and V-ATPase inhibition as an inhibitory mechanism to prevent cell migration and invasiveness in melanoma. Biochim. Biophys. Acta Gen. Subj. 1862(2018) 684-691. https://doi.org/10.1016/j.bbagen.2017.12.006.

[9] J. Couto-Vieira, P. Nicolau-Neto, E.P. Costa, F.F Figueira, T.A. Simão, A.L. Okorokova-Façanha, L.F. Ribeiro Pinto, A.R. Façanha, 2020. Multi-cancer VATPase molecular signatures: A distinctive balance of subunit $\mathrm{C}$ isoforms in $\begin{array}{llll}\text { esophageal } & \text { carcinoma. } & \text { EBioMedicine. } & 51,\end{array}$ https://doi.org/10.1016/j.ebiom.2019.11.042.

[10] B. X. Martins, R. F. Arruda, G. A. Costa, H. Jerdy, S. B. de Souza, J. M. Santos, W. R. de Freitas, M. M. Kanashiro, E. C. Q. de Carvalho, N. F. Sant'Anna, F. Antunes, R. Martinez-Zaguilan, S. Souad, A. L. Okorokova-Facanha, A. R. Facanha, Myrtenal-induced V-ATPase inhibition - A toxicity mechanism behind tumor cell death and suppressed migration and invasion in melanoma. Biochim. $\begin{array}{lllll}\text { Biophys. } & \text { Acta } & \text { Gen. } & \text { 1863(2019): }\end{array}$ https://doi.org/10.1016/j.bbagen.2018.09.006.

[11] J.M. Santos, R. Martínez-Zaguilán, A. R. Façanha, F. Hussain, S.R. Sennoune, Vacuolar $\mathrm{H}^{+}$-ATPase in the nuclear membranes regulates nucleocytosolic proton gradients. Am. J. Physiol. - Cell Physiol. 311(2016) C547-C558. https://doi.org/10.1152/ajpcell.00019. 
[12] B.A. Webb, M. Chimenti, M.P. Jacobson, D.L. Barber, Dysregulated pH: a perfect storm for cancer progression. Nat. Rev. Cancer. 11(2011) 671-677. https://doi.org/10.1038/nrc3110.

[13] R. Martinez-Zaguilan, R.M. Lynch, G.M. Martinez, R.J. Gillies, Vacuolar-type $\mathrm{H}^{+}$-ATPases are functionally expressed in plasma membranes of human tumor cells. Am. J. Physiol. 265(1993) C1015-C1029. https://doi.org/10.1152/ajpcell.1993.265.4.C1015.

[14] A. Velasco, E. Bussaglia, J. Pallares, X. Dolcet, D. Llobet, M. Encinas, N. Llecha, J. Palacios, J. Prat, X. Matias-Guiu, PIK3CA gene mutations in endometrial carcinoma: correlation with PTEN and K-RAS alterations. Hum Pathol. ;37(2006); 1465-72. doi: 10.1016/j.humpath.2006.05.007.

[15] A.H. Mohammad, S.H. Kim, N. Bertos, W. El-Assaad, I. Nandi, H. Smith, J. Yang, O.J. Chen, I. Gamache, T. Rao, B. Gagnon, T. Gruosso , M.L. Tremblay, N. Sonenberg, M.C. Guiot, W. Muller, M. Park, J.G. Teodoro, Elevated V-ATPase Activity Following PTEN Loss Is Required for Enhanced Oncogenic Signaling in Breast Cancer. Mol. Cancer Res. 18(2020) 1477-1490. https://doi.org/10.1158/1541-7786.MCR-20-0088. 
a

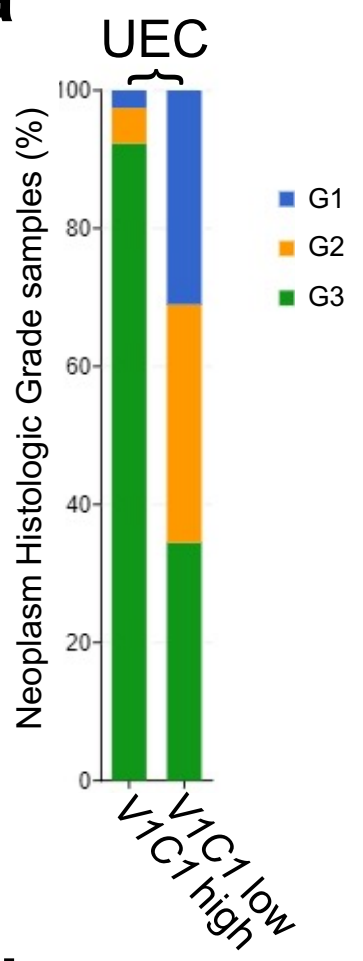

d

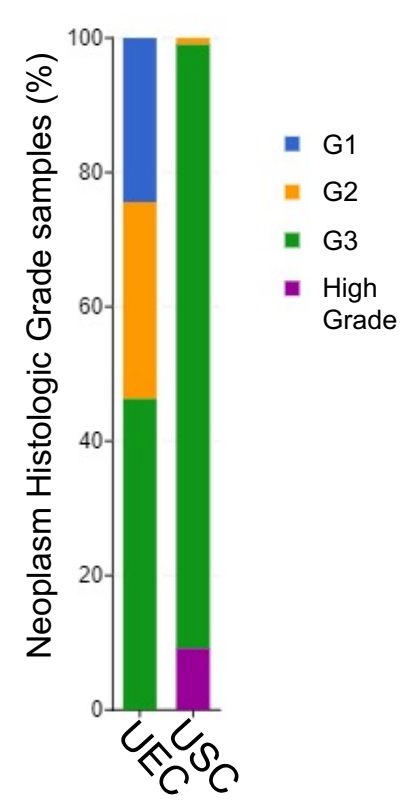

b
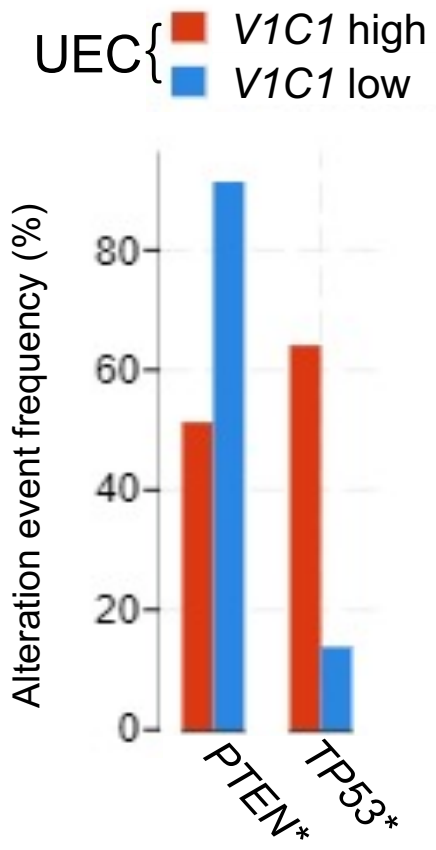

e

USC

UEC

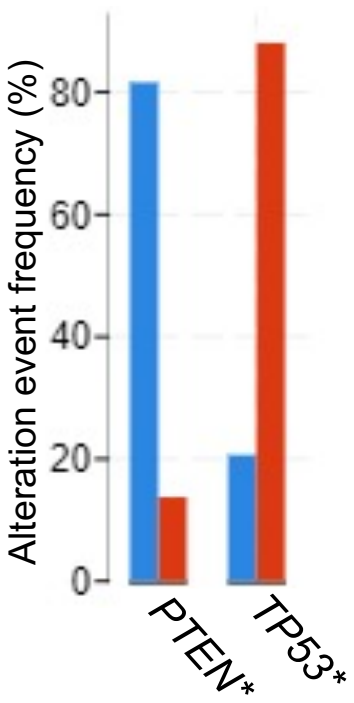

C

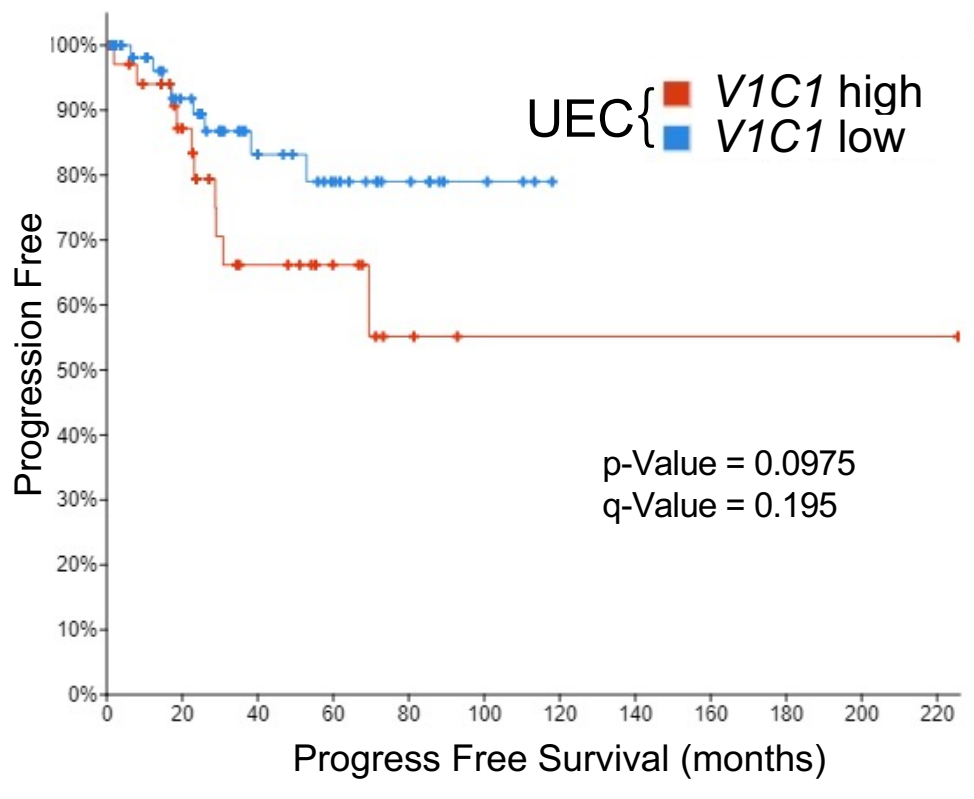

f

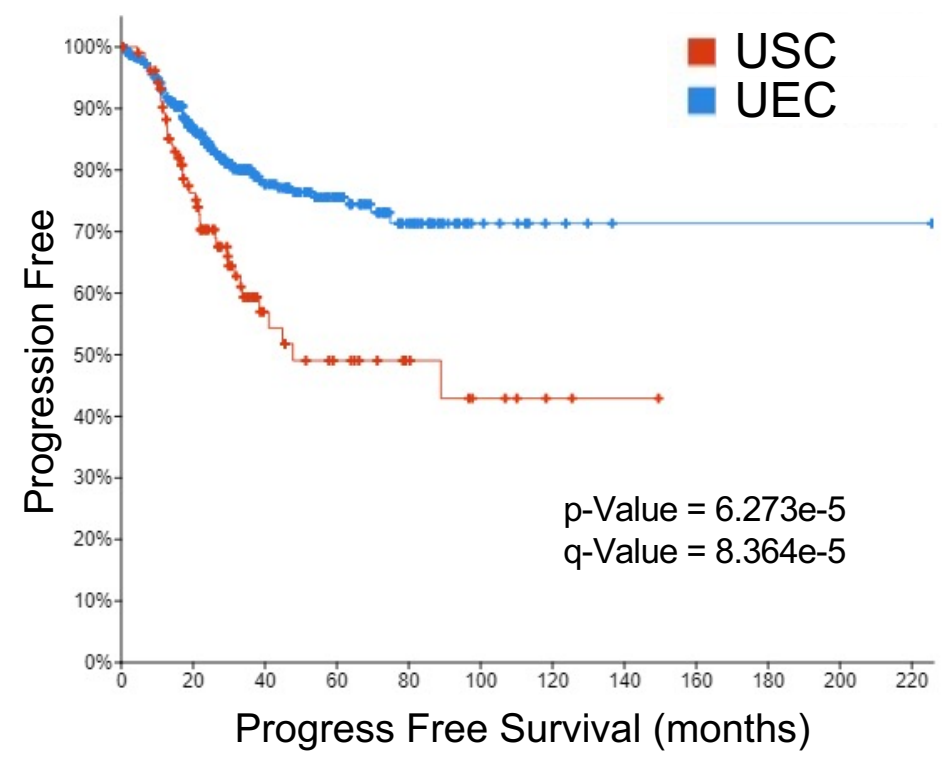

Fig. 1. Association between the expression of the $\mathrm{V}-\mathrm{H}^{+}$-ATPase $\mathrm{C} 1$ isoform subunit, grading, and survival in endometrial carcinoma. Analysis of ATP6V1C1 high and low expression groups in UEC (a,b,c); comparison between UEC and USC (d, e, f). Tumor differentiation grade ( $\mathbf{a}$ and $\mathbf{d}$ ); most frequently altered genes in the ATP6V1C1 high and low expression groups (b and $\mathbf{e}$, asterisks represent $\mathrm{p}$-value $<0.005$ ); Kaplan-Meier curve for progression-free survival in relation to ATP6V1C1 expression in UEC (c) and comparing UEC and USC ((f); log-rank test values are indicated). Abbreviations: PTEN, phosphatase and tensin homologue; TP53, tumor protein p53; UEC, uterine endometrioid carcinoma; USC, uterine serous carcinoma. 